\title{
Labour with low dose epidural analgesia: maternal perception and fetal outcome
}

\author{
Vasudha Sawant*, Archana Kumbhar
}

Department of Obstetrics and Gynecology, D. Y. Patil University, Kolhapur, Maharashtra India

Received: 14 December 2017

Accepted: 08 January 2018

\section{*Correspondence:}

Dr. Vasudha Sawant,

E-mail: vasudhaswnt@gmail.com

Copyright: (C) the author(s), publisher and licensee Medip Academy. This is an open-access article distributed under the terms of the Creative Commons Attribution Non-Commercial License, which permits unrestricted non-commercial use, distribution, and reproduction in any medium, provided the original work is properly cited.

\begin{abstract}
Background: Experiencing labour pains and giving birth to infant is normal physiological process. Though it is a natural phenomenon, it produces severe pain which requires analgesia to relieve pain during labour. The objective of this study was to compare effects of low dose epidural analgesia verses no analgesia during labour on mother and fetus.

Methods: Here in this study we have assessed effect of epidural analgesia on mother and fetus. Total we have taken 60 women in age group of 20-26 years with full term pregnancy (37-42 weeks). Those who have entered spontaneous labour with vertex presentation, without any previous uterine surgery, clinically adequate pelvis. We had divided these women in 2 groups, 30 were given epidural analgesia and 30 without any analgesia. Variables recorded were pain score during labour using VAS, duration of labour during each stage, mode of delivery, Apgar score of newborn at 1 minute and 5 minutes.

Results: Present study shows that duration of first stage of labour in epidural and non-analgesia group are same. Second stage of labour is prolonged in epidural group than non-analgesia group. Both groups had normal APGAR score. Epidural analgesia is not associated with any change in mode of delivery. Visual analogue scale is good with epidural analgesia.

Conclusions: There was no significant difference in first stage of labour in both group. Second stage of labour was slightly prolonged in EA group than control, but it was less than two hours. No harmful neonatal outcome in epidural analgesia.
\end{abstract}

Keywords: APGAR Score, Epidural analgesia, Labour, VAS score

\section{INTRODUCTION}

Experiencing labour pains and giving birth to infant is normal physiological process. Though it is a natural phenomenon, it produces severe pain which requires analgesia to relieve pain during labour.

Pain during the first stage of labour originates primarily in the cervix and the low uterine segment. ${ }^{1}$ Dilatation of the cervix and lower uterine portion leads to tissue distension, stretching out, and tearing. During the late first stage and second stage of labour (complete cervical dilation until delivery) the fetus descends in the birth canal and the progressively increased pressure of the foetus on the vagina and perineum become additional resources of pain.

Distension of the birth canal triggers powerful stretching and tearing of fascia and subcutaneous tissues and pressure on the skeletal muscles of the perineum. Painful urges from the lower uterine segment and cervix are transmitted via visceral afferent nerve fibres which go 
along with sympathetic nerve fibres and enter the spinal cord at the tenth, eleventh, and twelfth thoracic and first lumbar spinal portions. Somatic sensory impulses from the vagina and perineum are transmitted via the pudental nerves to the second, third and fourth sacral spinal segments.

Becoming a common problem of visceral pain, the pain of the first stage of labour is often referred to the dermatomes given by the same spinal cord segments that receive input from the uterus and cervix (T10 to L1). Additionally, during the late first stage and second stage of labour, stimulation of pain-sensitive structures within the pelvic cavity, and pressure on a single or more root base of the lumbo sacral plexus may bring about hurting, burning, or cramping distress in the thigh, lower limbs and back. Stimulation of these structures plays a role in pain referred to the lower lumbar and sacral portions.

Epidural and intrathecal blockade (neuraxial blockade) provides complete analgesia for both the first and second stages of labour.

Numerous physical and psychological factors may influence the intensity and duration of labour pain and suffering. Physical factors include maternal age group, parity, and maternal condition, the condition of the cervix at the starting point of labour, and the relationship of the size and position of the foetus to the size of the birth channel. Many of these factors are interrelated. Generally, elderly nulliparas experience longer and more painful labours than younger nulliparas. ${ }^{2}$

The parous cervix commences to soften even before the onset of labour and is less sensitive than the nulliparous cervix. The intensity of uterine contractions in early labour seems to be greater in nulliparous than parous women, whereas the reverse is true as labour progresses. Dystocia caused by a contracted pelvis, a big baby, or abnormal presentation or position is usually associated with greater pain.

Ladies who go on to have a caesarean delivery after labor have more breakthrough pain during epidural analgesia and require higher opioid doses during systemic analgesia than women who deliver vaginally. ${ }^{3}$ A history of dysmenorrhea, maternal fatigue, and general debility are associated with higher levels of pain. ${ }^{2}$

\section{METHODS}

The objectives of this study were to observe the effects of epidural analgesia in pain relief during labour progress and mode of delivery and the APGAR score of the fetus and to compare the outcome in epidural and no epidural group.

The present study was a prospective observational study conducted in a tertiary care hospital. D.Y. Patil Hospital and Research Institute, Kadamwadi, Kolhapur.
Registration of patients was from May 2014 to October 2016. They were registered when admitted under Obstetrics and Gynaecology Department. At the time of registration, the patients with exclusion criteria were not enrolled for study.

\section{Inclusion criteria}

- $\quad$ All patients with full term pregnancy (37-42 weeks)

- Those who have entered spontaneous labour with vertex presentation

- Those without any previous uterine surgery

- Clinically adequate pelvis, cephalopelvic disproportion ruled out.

\section{Exclusion criteria}

- Pregnancy with medical disorder (heart disease, diabetes mellitus)

- Preeclampsia

- Eclampsia

- Previous LSCS.

The data is collected in predesigned proforma. The variables are duration of labour, mode of delivery, APGAR score of newborn at 1 minute and 5 minutes, pain perceived by the subject.

This study design was developed in association with anaesthetist and approved by the local ethical committee.

Study patients were allocated in two groups:

\section{Group A}

The women in early labour who desired epidural analgesia (study group EA).

\section{Group B}

The women in labour who were not willing for labour analgesia (control group NA).

The women in labour who have fulfilled inclusion criteria are enrolled in the study. They were counselled when they were admitted in labour room, during $1^{\text {st }}$ stage of labour. The aims of the study were explained to them. Detailed history was taken according to the proforma. General physical examination done. Systemic examination including per abdominal examination, per vaginal examination done to rule out cephalopelvic disproportion.

After counselling we have taken informed written valid consent for the epidural analgesia. A good IV access 18 or 16 gauze was established, and preloading was done with $500 \mathrm{ml}$ of ringer lactate. Throughout the procedure maternal heart rate, maternal blood pressure and foetal heart rate were monitored. A Lumbar epidural catheter no 
18 was placed under strict aseptic techniques by Anaesthesiologist. A test dose was given with $3 \mathrm{ml}$ of $2 \%$ lignocaine with adrenaline i.e. 1 in 2 lac ratios for confirmation of position of catheter in epidural space. After test dose $10 \mathrm{ml}$ of $0.1 \%$ Bupivacaine and $40 \mathrm{mcg}$ of Fentanyl was given slowly.

Maternal heart rate, blood pressure and level of block were monitored every 5 minutes for first 15 minutes following insertion, then every half hour throughout the procedure. Top up was given as per requirement i.e. as mother starts having pain sensation. Top up dose was 10 $\mathrm{ml}$ bolus of $0.1 \%$ bupivacaine $+2 \mathrm{mcg} / \mathrm{ml}$ fentanyl on demand was given by anaesthesiologist after strict hand wash and alcohol rub. Prior to each top up - fetal heart rate, level of block, maternal pulse and blood pressure were assessed.

Maternal pain severity was assessed by Visual Analogue Scale (VAS).

VAS is unidimensional measure of pain intensity. It comprises of horizontal line or vertical line usually 100 $\mathrm{mm}(10 \mathrm{~cm})$, anchored by 2 verbal descriptors, one for each symptom extreme.

Table 1: Maternal profile.

\begin{tabular}{|lllll|} 
No pain & & & Severe pain \\
$0 \mathrm{~mm}$ & $4 \mathrm{~mm}$ & $44 \mathrm{~mm}$ & $74 \mathrm{~mm}$ & $100 \mathrm{~mm}$ \\
\hline
\end{tabular}

Patient was asked to place a finger over the scale, according to the intensity of pain felt by her. Using a ruler, the score is determined by distance $(\mathrm{mm})$ on $10 \mathrm{~cm}$ line between no pain and patients mark providing a range of scores $0-100 \mathrm{~mm}$.

We have used following cut points on the VAS scale.

- $\quad$ No pain (excellent satisfaction): 0-4 mm

- Mild pain (good satisfaction): 5-44 mm

- Moderate pain (average satisfaction): 45-74 mm

- Severe pain (poor satisfaction): 75-100 mm.

The obstetric management of the women in labour in both groups was similar. The intrapartum management included maternal monitoring in the form of pulse, blood pressure, assessment of uterine contractions and cervical dilatation, effacement. Similarly, fetal monitoring was done with continuous electronic monitor. Artificial rupture of membranes was performed as a part of active management of labour. The intensity of pain during uterine contractions was assessed by VAS. Pelvic examination was performed every 2 hours to assess the labour progress in first stage of labour. When uterine contractions were inadequate oxytocin infusion was started at the rate of $6 \mathrm{mu} / \mathrm{min}$ and increasing by 4 $\mathrm{mu} / \mathrm{min}$ every 15 minutes until there were strong uterine contractions i.e. 4-5 contractions per min lasting for 45 seconds - 1 minute. The decision regarding intervention for instrumental delivery or operative delivery was decided as per the maternal or fetal indications.

Variables recorded were

- $\quad$ Pain score during labour using VAS

- Duration of labour during each stage

- Mode of delivery

- Apgar score of newborn at 1 minute and 5 minutes.

Data were expressed as mean \pm SD and analysed using Student $\mathrm{t}$ test and chi square test where appropriate. $\mathrm{P}$ $<0.05$ was considered statistically significant. The collected data was compiled in Microsoft excel 2013 and analysed using SPSS software 23 version.

\section{RESULTS}

Both the groups were matched with respect to characters like maternal age, height, weight, gestational age. Total number of patients in this study was 60. Majority of patients were between 20-26 years with mean age of 23.2 years. There were 18 primigravida and 12 multigravidas in both groups. Cervical parameters were comparable in two groups at the time of enrolment in study (Table 2).

Table 2: Effect on labour and maternal outcome.

\begin{tabular}{|c|c|c|c|}
\hline & $\begin{array}{l}\text { EA group } \\
(\mathbf{n}=\mathbf{3 0})\end{array}$ & $\begin{array}{l}\text { NA group } \\
(\mathrm{n}=30)\end{array}$ & $\begin{array}{l}P \\
\text { value }\end{array}$ \\
\hline \multicolumn{4}{|c|}{ Duration of labour (min) } \\
\hline $1^{\text {st }}$ stage & $381.16 \pm 61.75$ & $370.03 \pm 79.33$ & 0.54 \\
\hline $2^{\text {nd }}$ stage & $71.63 \pm 10.11$ & $23.00 \pm 10.30$ & $<0.001$ \\
\hline $3^{\text {rd }}$ stage & $7.76 \pm 3.08$ & $7.6 \pm 2.99$ & 0.83 \\
\hline $\begin{array}{l}\text { Need for } \\
\text { oxytocin }\end{array}$ & 9 & 6 & 0.37 \\
\hline \multicolumn{4}{|c|}{ Cardiotocographic study } \\
\hline Reassuring & 27 & 28 & 0.89 \\
\hline Non reassuring & 3 & 2 & \\
\hline \multicolumn{4}{|c|}{ Mode of delivery } \\
\hline Vaginal & 25 & 26 & 0.697 \\
\hline Instrumental & 03 & 01 & 0.27 \\
\hline $\begin{array}{l}\text { Caesarean } \\
\text { section }\end{array}$ & 02 & 03 & 0.63 \\
\hline Complications & nil & nil & \\
\hline
\end{tabular}

Average duration of first stage of labour in EA group is $381 \mathrm{~min}$ at that in NA group is $370 \mathrm{~min}$. Average duration of second stage was $71.63 \mathrm{~min}$ and 23.00 in EA group and NA group respectively. Although $2^{\text {nd }}$ stage is slightly prolonged, it is in normal duration of second stage i.e less than 2 hours.

Average duration of third stage of labour in EA group was 7.76 minutes and that in NA group is 7.6 minutes. By Wilcoxon signed rank test there is no significant difference is observed in mean duration of $1^{\text {st }}$ and $3^{\text {rd }}$ stage of labour ( $p$ value 0.54 ), but there is significant difference in $2^{\text {nd }}$ stage of labour in both groups ( $\mathrm{p}$ value < 0.001) (Table 2). 
Table 3: Efficacy of analgesia.

\begin{tabular}{|llll|}
\hline VAS score & $\begin{array}{l}\text { EA } \\
(\mathbf{n = 3 0})\end{array}$ & $\begin{array}{l}\text { NA }(\mathbf{n} \\
=30)\end{array}$ & P value \\
\hline No pain (0-4) & 24 & 0 & $<0.0001$ \\
\hline Mild pain (5-44) & 4 & 3 & 0.71 \\
\hline Moderate pain (45-74) & 2 & 8 & 0.0284 \\
\hline Severe pain (75-100) & 0 & 19 & 0.0011 \\
\hline Willingness for EA in & next pregnancy & \\
\hline EA group & $\mathbf{\%}$ & NA group & $\mathbf{\%}$ \\
\hline 30 & 100 & 22 & 73 \\
\hline 0 & 0 & 8 & 27 \\
\hline
\end{tabular}

In EA group 24 patients have perceived almost no pain which is excellent pain relief with p value of, 0.0001 statistically significant. No patient in NA group was painfree. In NA group 19 patients had severe pain in contrast nobody in EA group had severe pain which is statistically significant. In EA group 4 patients had mild pain and 2 patients had moderate pain. In NA group 11 have perceived mild to moderate. All women in EA group were willing for repeat epidural analgesia in next pregnancy and $73 \%$ women in NA group were interested in epidural analgesia in next pregnancy (Table 3 ).

In EA group 25 patients had vaginal delivery, 3 instrumental vaginal delivery and 2 underwent caesarean section. In NA group 26 patients had vaginal delivery, 1 instrumental delivery and 3 required caesarean section. There were no intrapartum or postpartum complications in both groups. Indications for caesarean section in both groups were fetal distress, meconium stained amniotic fluid, non-progress of labour. In NA group one caesarean section was done on demand in view of intolerability of pain. As $\mathrm{p}$ values for mode of delivery are more than 0.05 difference observerd in both EA and NA groups regarding mode of delivery is not statistically significant (Table 2).

Table 4: Neonatal outcome.

\begin{tabular}{|llll|}
\hline Parameter & $\begin{array}{l}\text { EA group } \\
(\mathrm{n}=30)\end{array}$ & $\begin{array}{l}\text { NA group } \\
(\mathrm{n}=30)\end{array}$ & $\begin{array}{l}\mathrm{P} \\
\text { value }\end{array}$ \\
\hline APGAR score & & & \\
\hline 1 min & $7.9 \pm 1.18$ & $8.03 \pm 1.19$ & 0.673 \\
\hline 5 min & $9.37 \pm 1.03$ & $9.43 \pm 0.93$ & 0.814 \\
\hline Birth weight & $2.74 \pm 0.32$ & $2.73 \pm 0.27$ & 0.896 \\
\hline NICU admission & 0 & 0 & \\
\hline
\end{tabular}

Both group neonates had good neonatal APGAR score at 1 as well 5 minutes, none required NICU admission (Table 4).

\section{DISCUSSION}

Results of present study demonstrated that epidural analgesia provides excellent pain relief than no analgesia similar to a study by Anim S et al. ${ }^{4}$ In this study we have used lower concentration of bupivacaine $(0.1 \%)$ to avoid the decrease of intensity of uterine contractions also to allow the women to bear down effectively. To provide effective analgesia fentanyl was added which further reduced the amount of bupivacaine needed during labour. ${ }^{5,6} \mathrm{We}$ instituted epidural analgesia only after confirming that patient has entered active stage of labour.

Perception of pain in EA group was very low with $100 \%$ of patients giving good VAS score. Patients acceptability in EA group was $100 \%$ all of them were interested to take epidural analgesia in next labour if they desire to become pregnant again. In non-epidural group only $73 \%$ patients tolerated pain very well and were happy without any analgesia, but $27 \%$ patients had experience of severe pain, so they were willing to take epidural analgesia in next pregnancy if desired.

In the present study mode of delivery was either vaginal, instrumental or caesarean section in both groups. In regard of mode of delivery there was no difference observed in both groups, $\mathrm{p}$ values not significant, our study results are in agreement with several previous studies. $^{7-9}$

There was no difference in mean duration of first stage of labour in both groups with $p$ value of 0.54 which is statistically insignificant, our results were similar to study by Wesam F M et al. ${ }^{8}$ Second stage of labour was slightly prolonged in EA group than NA group with mean of 71.63 minutes and 23 respectively which gives significant $\mathrm{p}$ value of $<0.001$ which is similar to study by Agrawal D et al. ${ }^{7}$ Present study results of no difference in first stage and prolonged second stage are similar to several previous studies. ${ }^{10-12}$

Present study showed no difference in APGAR scores in both groups similar to studies by Agrawal $\mathrm{R}$ et al and Mousa et al. ${ }^{7,8}$

\section{CONCLUSION}

Epidural analgesia during labour appears to have significant pain relief as compared to no analgesia during labour. Patients satisfaction and willingness in next pregnancy is noted in analgesia group. There was no adverse effect regarding neonatal outcome.

\section{Funding: No funding sources \\ Conflict of interest: None declared \\ Ethical approval: The study was approved by the Institutional Ethics Committee}

\section{REFERENCES}

1. ADAPTE Collaboration. ADAPTE manual for guideline adaptation, version 1.0. Canada: Guidelines International Network. 2007.

2. Dutta DC. Textbook of Obstetrics. $13^{\text {th }}$ edition. New Central Book Agency (P) Ltd. Kolkata; 2013:113-25. 
3. Friedman EA. The graphic analysis of labor. Am J Obstet Gynecol. 1954;686:1568-75.

4. Loubert C, Hinova A, Fernando R. Update on modern neuraxial analgesia in labour: a review of the literature of the last 5 years. Anaesthesia. 2011;66(3):191-212.

5. Campbell DC. Labor analgesia: what's new and PECA too? Can J Anaesth. 2003;50:R8.

6. D'Angelo R. Epidural PCA during labor. Am Soc Anesthes Newsl. 2001;65:16-8.

7. Agrawal D, Makhija B, Arora M, Haritwal A, Gurha P. The effect of epidural analgesia on labour, mode of delivery and neonatal outcome in nullipara of India, 2011-2014. J Clin Diag Res. 2014;8(10):OC03.

8. Mousa WF, Al-Metwalli R, Mostafa M. Epidural analgesia during labor vs no analgesia: a comparative study. Saudi J Anaesthesia. 2012;6(1):36.
9. Sienko J, Czajkowski K, Swiatek-zdzienicka M. Epidural analgesia and the course of delivery in term primiparas. Ginekol Pol. 2005;76:806-11.

10. Anim-Somuah M, Smyth RM, Jones L. Epidural versus non-epidural or no analgesia in labour. Cochrane Database Syst Rev. 2011:CD000331.

11. Raja KS, Tasleem H. Influence of epidural analgesia on frequency of instrumental delivery and duration of labour. Rewal Medical J. 2009;34:86-8.

12. Fouzia A, Shazia S, Gulishan H. Fetomaternal outcome of epidural analgesia during labour. J Surg Pakistan. 2010;15:151-4.

Cite this article as: Sawant V, Kumbhar A. Labour with low dose epidural analgesia: maternal perception and fetal outcome. Int J Reprod Contracept Obstet Gynecol 2018;7:689-93. 